\title{
Original Research \\ Home Management of Oral Anticoagulation via Telemedicine Versus Conventional Hospital-Based Treatment
}

\author{
Henry Christensen, M.Sc.IT, Jens-Jacob Lauterlein, M.D., ${ }^{1}$ \\ Patricia D. Sørensen, M.D., ${ }^{1}$ Eva R.B. Petersen, M.D., ${ }^{1}$ Jonna \\ S. Madsen, M.D., Ph.D., ${ }^{1,2}$ and Ivan Brandslund, M.D., D.M.Sc. ${ }^{1,2}$ \\ ${ }^{1}$ Department of Clinical Biochemistry, Vejle Hospital, Vejle, \\ Denmark. \\ ${ }^{2}$ Institute of Regional Health Research, University of Southern \\ Denmark, Odense, Denmark.
}

\begin{abstract}
Background and Objective: We have developed an expert computer system for the control of oral anticoagulation therapy, accessible by the patients via their own computer. To investigate if the weekly measurement and dosing of international normalized ratio (INR) at home using the online Internet-based system was superior to conventional treatment, we performed a randomized, controlled trial. Patients and Methods: All 669 patients in our anticoagulation clinic were asked to participate in the trial, providing that they had Internet access and could use the CoaguChek XS system. A total of 140 patients were included and randomized to (A) once weekly measurement and report online, (B) twice weekly measurement and report online, and (C) continued conventional treatment with INR measurement in the lab every 4 weeks and dose adjustment by letter. Results: Group A had 79.7\% (95\% CI 79.0-80.3) of time in therapeutic range (TTR), group B 80.2\% (95\% CI 79.4-80.9) of TTR, and group C 72.7\% (95\% CI 71.9-73.4) TTR. Groups $A$ and B perform statistically significantly better than the conventional group $C$, with a difference of TTR of $7 \%$ points $\left(\mathrm{p}<2.2 \times 10^{-16}\right)$, whereas no difference was seen between $A$ and $B$. Conclusion: Home measurement of INR and the reporting and dosing of results online once $a$ week increase TTR from $72 \%$ to $79 \%$ as compared to conventional computer-assisted monitoring in an anticoagulation clinic.
\end{abstract}

Key words: telemedicine, INR, oral anticoagulation

\section{Introduction}

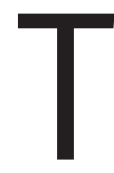

raditionally oral anticoagulation with warfarin or phenprocoumon has been monitored in patients visiting hospitalbased clinics on a monthly basis. Usually, the patient presents to an office or at a laboratory drawing center, where a venous blood sample is taken and transported to the laboratory for analysis. In the laboratory a prothrombin time is performed, and the result is expressed in international normalized ratio (INR) as defined by the World Health Organization (WHO), making the result worldwide transferable and usable. After a variable length of time, in some hospitals within an hour and in others after a day, the result is available to the patient's physician. The physician reviews the patients result and after consulting the patient's medical record, with information on present dose of drug, previous INR level, target for INR, and therapeutic range according to diagnosis, determines a clinical course of action and/or drug dose adjustment. The patient is contacted, usually by writing and in some cases by phone, and is given the instructions for drug intake and next date of measurement. ${ }^{1}$ This is traditionally managed in a paper record system.

Due to an unacceptable frequency of adverse events caused by mistakes or failures in correct dosing or transfer of prescription doses to paper, many clinics in Denmark have started using electronic expert systems or electronic patient record systems for the managing of these chronic patients.

Due to the widening indications for oral anticoagulation especially atrial fibrillation during the last 15 years and the increase in age of the population, the number of patients on anticoagulation has increased in Denmark from estimated 10,000 patients out of 5.5 mill population in treatment in 1993 to 90,000 in 2007. ${ }^{2}$ The current demand for oral anticoagulation therapy is expected to increase up to sixfold by $2050^{3}$ and this imposes a severe burden on the healthcare system.

In our local clinic the number of patients has increased from 250 to around 700. To cope with this burden we developed our AC anticoagulation computer system (CSO/AC; IntraMed A/S, Værløse, Denmark) to be accessible for the patients via the Internet. ${ }^{4}$ Figure 1 shows the user interface, and Figure 2 shows the architecture of the installation. According to Danish law, this is only legal if security rules are followed, including controlling identity via both civil registration number and a digital signature system (OCES), administered by the Danish National IT and Telecom Agency. ${ }^{5}$

From 2006 to 2008, we conducted pilot studies on the system's functionality and also performed a pilot study with 15 patients on self-testing on the CoaguChek S system (Roche Diagnostics A/S, Hvidovre, Denmark), reporting the INR online to the CSO patient record system.

The reception of an INR measurement prompts an immediate demand for attention in the anticoagulation clinics computer screen. The attending doctor handles the patients within an hour, creating a letter of future dosage, accessible immediately on the patient's own PC.

Based on the patient experience with the functionality of the system and the convenience for the patients, saving time and transport expenses, we decided to find out, whether the system would increase quality of treatment, as measured by time in therapeutic range (TTR). ${ }^{6}$ 


\section{CHRISTENSEN ET AL.}

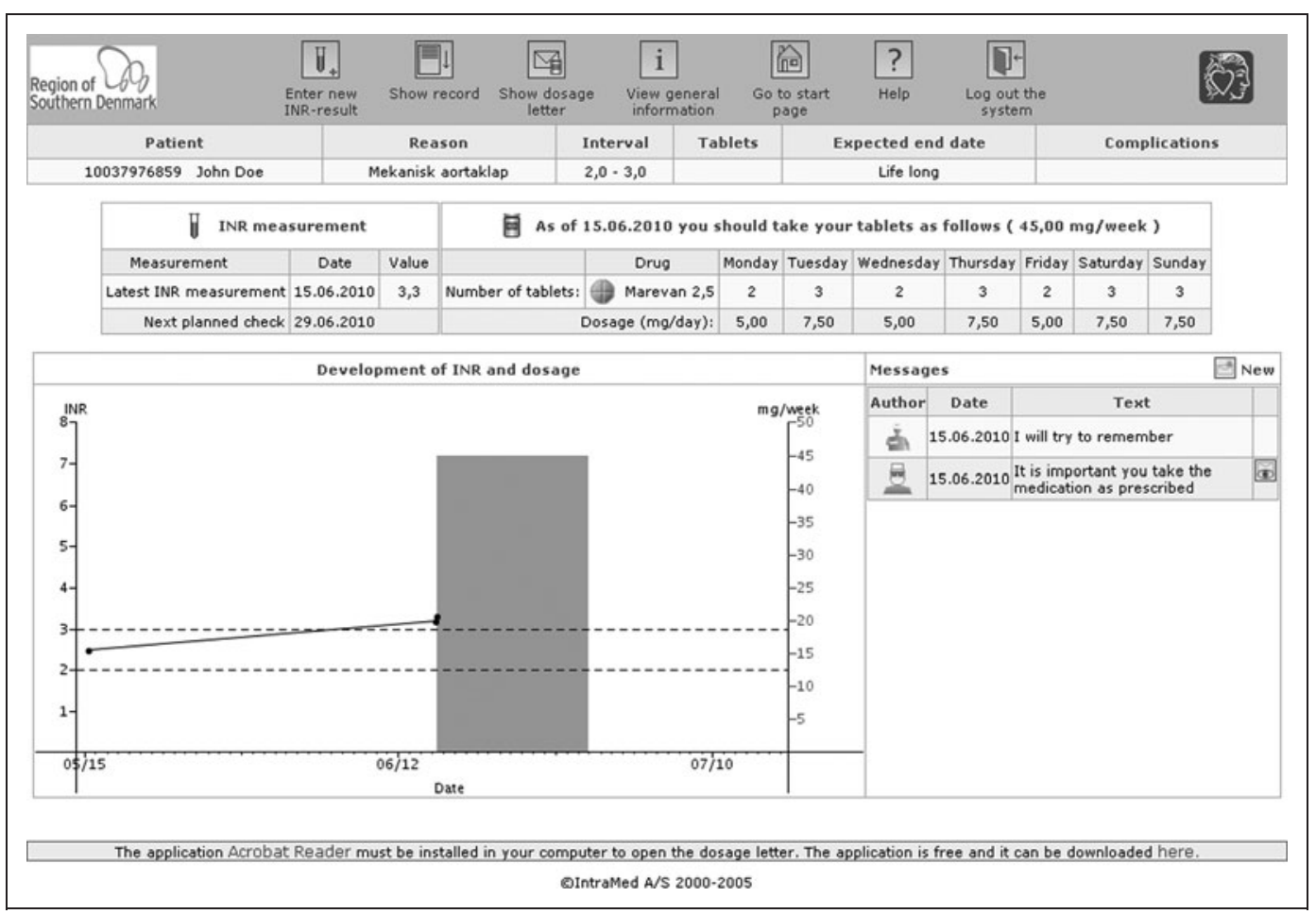

Fig. 1. User interface for the AC anticoagulation computer system.

it was seen that during 300 days of observation for the single patient the range of days within TR was from 150 to 300 days, the estimated standard deviation (SD) then 30 days. As the mean was 210 days and we wanted to detect an increase of 30 days, with a type 1 risk of $1 \%$ and a power to detect the difference of 95\%, 35 patients were needed in each group for at least 300 days. Hence, 140 patients were randomized to the three groups.

The primary variable was TTR as measured with the Rosendaal method in each arm. The difference in TTR between groups A, $\mathrm{B}$, and $\mathrm{C}$ was calculated using chi-squared test, $t$-tests, or the nonparametric equivalent where appropriate using the R-software (R Foundation for Statistical Computing, Vienna, Austria).

Each patient in groups A, B, and $\mathrm{C}$, respectively, was also

\section{Materials and Methods STUDY DESIGN}

A randomized, controlled trial (RCT) was carried out at the anticoagulation clinic in the Vejle County Hospital to test the hypothesis that patient self-testing (PST) using an online access to the anticoagulation (AC) clinic might be superior to standard anticoagulation control. All (669) patients in treatment at the AC clinic received a letter explaining about the investigation and they were asked-provided they had a computer, had Internet access, and were willing to measure with the point-of-care test system at home-whether they would like to participate in this three-armed controlled trial. Those willing to participate, 140 patients, were randomized to one of three groups: group A, measuring INR at home once a week; group B, measuring INR twice a week; and group $\mathrm{C}$, continuing regular visits to the $\mathrm{AC}$ clinic for the next year before being switched to the PST methodology.

This study was approved by the Science Ethics Committee in the Region of Southern Denmark (Project-ID: S-20080053). The primary outcome, quality of anticoagulation treatment, TTR for the single patient depending on each patients own therapeutic range during the study period, was recorded according to the Rosendaal method. ${ }^{6}$ Secondary outcomes were the number of INR measurements below 1.5 or above 5.0. Numbers of adverse clinical events were recorded but were too infrequent to be of value.

\section{SAMPLE SIZE AND STATISTIC ANALYSIS}

Our expectation was that the TTR would increase 10\% based on previous studies. ${ }^{7}$ Based on statistics for the conventional treatment, compared to the previous 12-month period if data were available, and statistics performed with the paired sample Wilcoxon rank sum test.

\section{STUDY POPULATION}

All included patients were on lifelong therapy and been in treatment for at least 6 months. They were asked to participate on the condition that they were willing to accept a randomization to a control group continuing conventional care for the next 12 months. The participants should be able to use the Internet and demonstrate their ability to use the CoaguChek XS system for measuring INR after a 1-h teaching session. Patients were excluded from group A if they had more than two intervals longer than 3 weeks without testing. In group B, patients excluded for having more than two intervals longer than 2 weeks. In group C, patients were excluded for having more than two intervals longer than 5 weeks. In all groups, patients were excluded if they had a one period longer than 60 days without testing.

\section{RECRUITMENT}

All participants received a letter asking them to participate and explaining the design of the study. Patients responding were further informed by the staff and evaluated for their ability to cope and participate in the investigation.

\section{EDUCATION AND TRAINING}

Patients in groups A and B were educated in using the computer interface and the CoaguChek XS point-of-care test system within $\sim 2 \mathrm{~h}$. All patients in treatment at the clinic are aware of the 


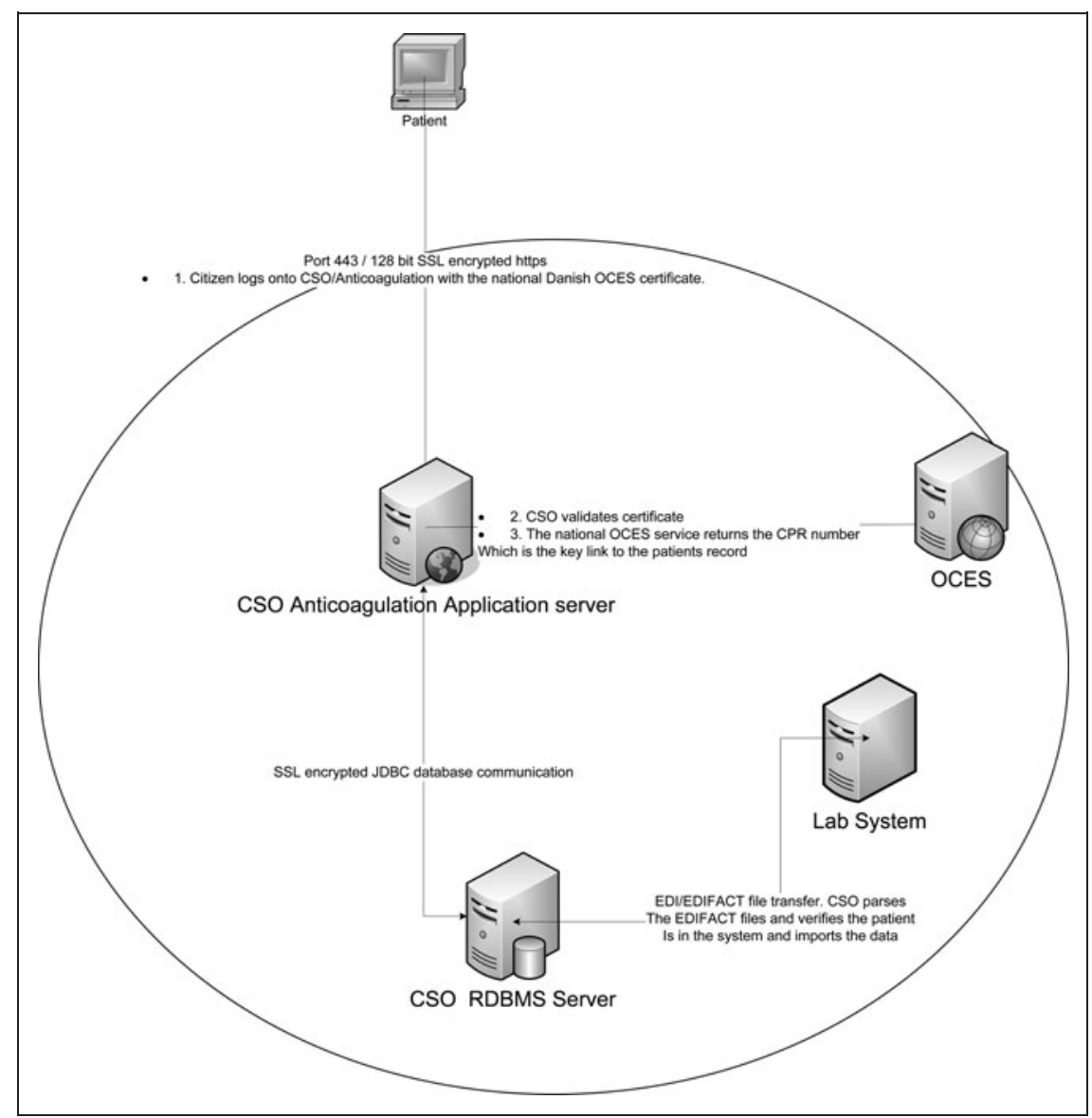

adjusting dose for the following period and reported via the system. If patients reported problems or asked questions on the parallel mail system, they were answered by the AC staff or contacted via telephone. The AC staff responded within $4 \mathrm{~h}$ to reported INR values. Patients not reporting their INR within the agreed time were alerted through mail by letter. Patients observing values below 1.5 or above 5 were alerted by the system to contact the clinic immediately as was the rule for changes exceeding biological possible limits. The doctors, three junior and two senior, in the clinic decided all changes in medication in the same way for groups $\mathrm{A}, \mathrm{B}$, and $\mathrm{C}$.

Every half-year the patients visited the clinic to make a parallel measurement on their point-of-care system with the laboratory method. All fulfilled the demand of maximum difference of 0.5 INR.

\section{TRADITIONAL MONITORING}

Patients randomized to group $\mathrm{C}$ visited the clinic according to the usual rules of measurements being maximum 4 weeks, but dependable on percentage change in warfarin-dose with shorter time interval. INR analysis was performed on a STAGO STA-R Evolution (DIAGNOSTICA STAGO, Asnières sur Seine, France) dose adjustments were performed by the attending doctor. The CSO/AC anticoagulation

Fig. 2. The architecture of the $A C$ anticoagulation computer system.

theoretical aspects of anticoagulation, mechanism of action, meaning and importance of INR values and target ranges, diet and lifestyle, and symptoms of over-coagulation, drug interaction, and compliance. Group C was not trained beyond this education.

The patients' ability to measure correctly was tested by comparing obtained values from the point-of-care instrument to the laboratory result. Patients and the point-of-care instrument were accepted if able to measure within 0.5 INR of difference. One patient was unable to measure within 0.5 and was excluded before randomization.

The randomization program QuickCalcs (GraphPad Software, Inc., La Jolla, CA) generated a random allocation sequence and the patients were assigned to group A, B, or C accordingly. The trial was unblinded. The patients received a manual for online access and reporting of their INR and further on the communication system connected to the reporting of the single INR measurement (e-mail system integrated in the EPJ-expert system). They entered the study immediately after training consecutively over a period of 1 year (from April 22, 2008).

\section{MANAGEMENT OF PST PATIENTS}

Group A measured once a week and group B twice a week and reported the single value, which was acted upon by the AC clinic by

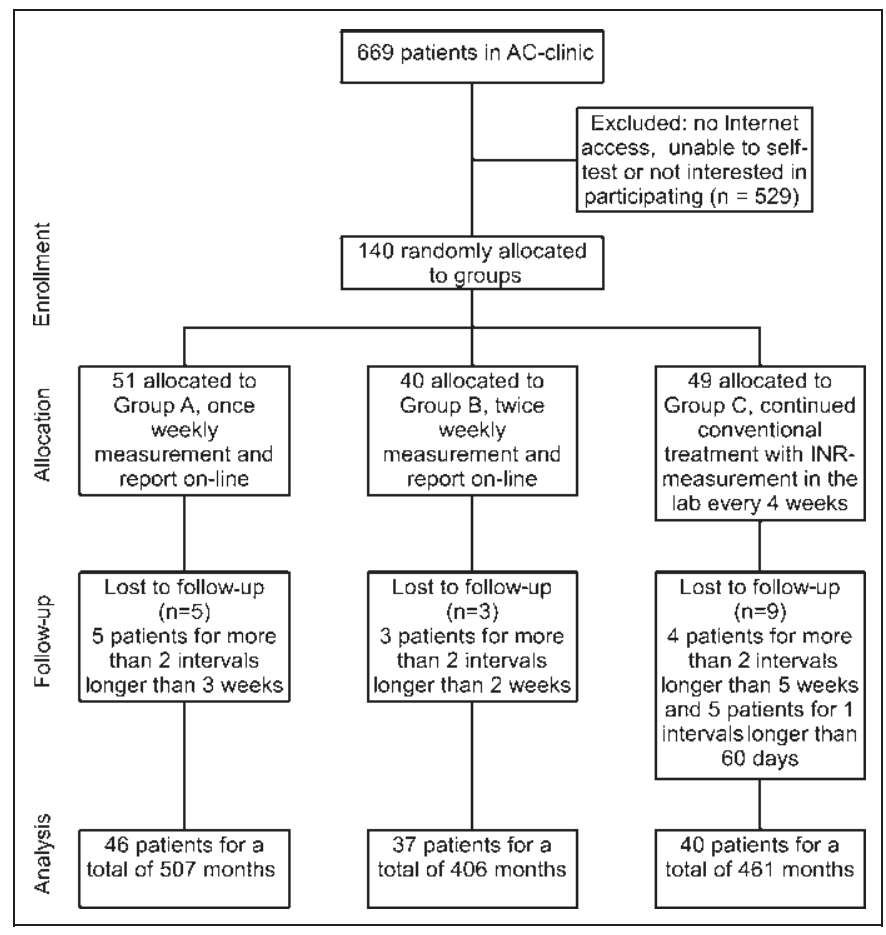

Fig. 3. Identification of eligible patients and patient enrollment. 


\section{CHRISTENSEN ET AL.}

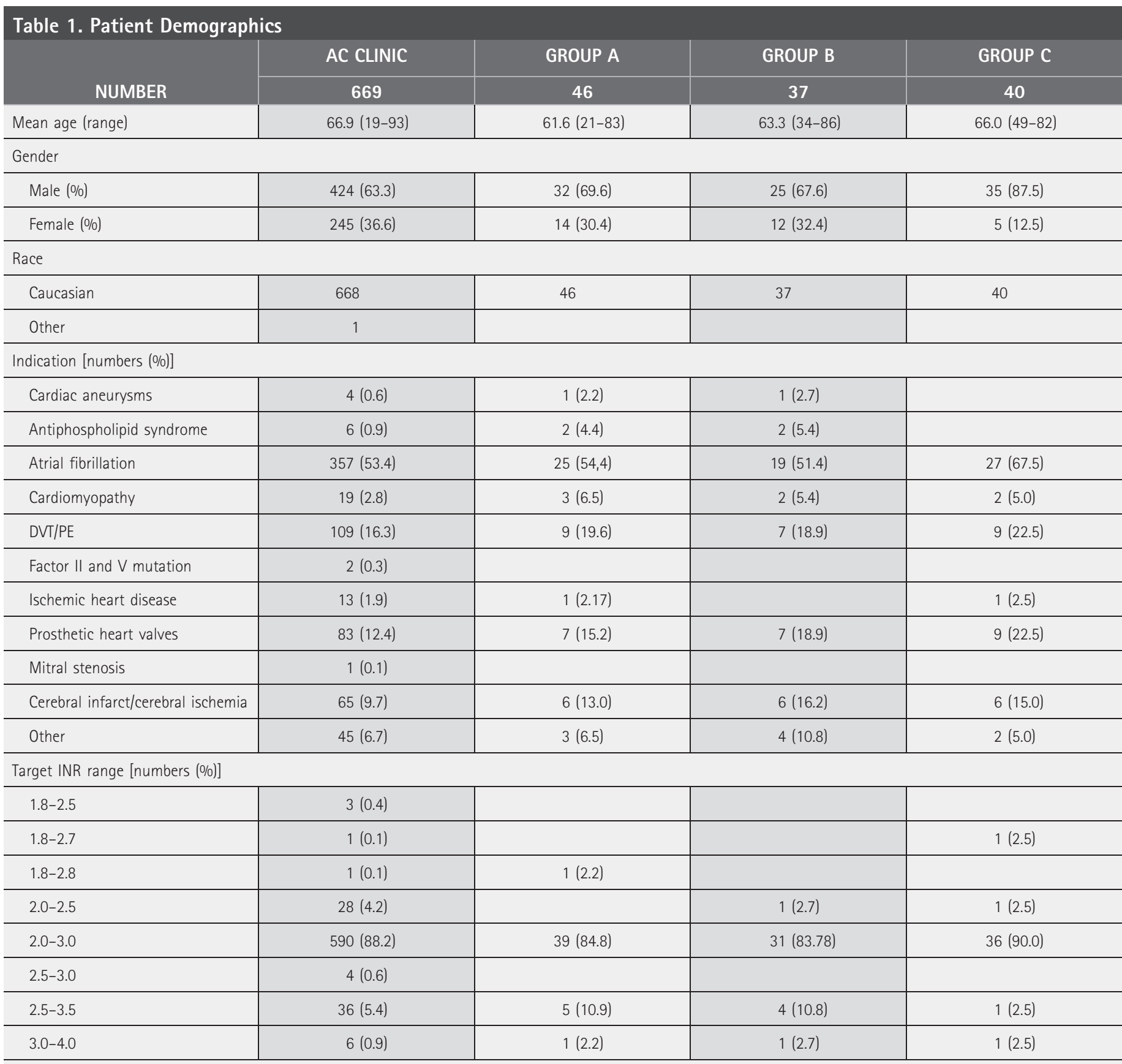

$A C$; DVT, deep venous thrombosis; $P E$, pulmonary embolism; INR, international normalized ratio.

expert system (IntraMed A/S) was used for decision support and registration. The expert system suggested both a new dose and a new measurement date both adjustable by the doctor.

\section{ADVERSE EVENT REPORTING}

Patients reported via the mail system or by telephone any incident during the period, including hospitalizations. Hospitalizations were recorded through a discharge letter from the department, and checked for every single patient in the electronic hospital database.

\section{Results}

STUDY POPULATION

One hundred forty patients were randomized for the three groups. The patients were randomized to the three groups as shown in Figure 3. 


\begin{tabular}{|c|c|c|c|c|}
\hline & ALL BEFORE TRIAL & A IN TRIAL & B IN TRIAL & C IN TRIAL \\
\hline $\begin{array}{l}\text { Mean frequency of } \\
\text { testing } \pm S D \text { in days }\end{array}$ & $21.3 \pm 11.2$ & $7.4 \pm 2.7$ & $4.1 \pm 1.8$ & $15.3 \pm 8.8$ \\
\hline $\begin{array}{l}\text { No. of extreme INR } \\
(<1.5,>5.0)(\%)\end{array}$ & $23(1.7)$ & $16(1.2)$ & $21(0.7)$ & $31(3.4)$ \\
\hline No. of <1.5 (\%) & $23(1.7)$ & $13(0.6)$ & $16(0.5)$ & $25(2.7)$ \\
\hline No. of $>5.0(\%)$ & $0(0.0)$ & $3(0.1)$ & $5(0.2)$ & $6(0.7)$ \\
\hline
\end{tabular}

SD, standard deviation.

This represented $\sim 20 \%$ of the anticoagulation clinic population as a whole. Seventeen patients were withdrawn for the following reasons. In group A, five persons were withdrawn for having more than two intervals longer than 3 weeks without testing. In group B, three patients were withdrawn for having more than two intervals longer than 2 weeks. In group C, four patients were withdrawn for having more than two intervals longer than 5 weeks and five patients were withdrawn for having one interval longer than 60 days without testing. In all circumstances they returned to the program. Absences were caused by personal and family reasons.

One hundred twenty-three $(n=123)$ completed the trial. Patient demographics and indication of anticoagulation are shown in Table 1 compared to regular AC clinic. There were no significant difference between the three groups, but the age and gender differed from the AC clinic in general. There was not found any significant difference between the groups and the AC clinic in the indication of anticoagulation and the target INR range.

\section{OUTCOME}

Data are shown in Tables 2 and 3.
The overall days in TR during the trial for the three groups were as follows: group A, 12,288 of 15,427 days in TR (79.7\%) (95\% CI 79.080.3); group B, 9,904 of 12,348 days (80.2\%) (95\% CI 79.4-80.9); group C, 10,195 of 14,026 days in TR (72.7\%) (95\% CI 71.9-73.4). Groups A and B performed statistically significantly better than the conventional group $\mathrm{C}$, with a difference in relative TTR of 7\% points $\left(p<2.2 \times 10^{-16}\right)$, whereas no difference was seen between A and B, once a week or twice a week.

The overall number of INR measurements in TR was in the same period: group A, 1,635 of 2,087 measurements (78.3\%) (95\% CI 76.580.1); group B, 2,407 of 2,979 measurements (80.8\%) (95\% CI 79.382.1); group C, 616 of 916 measurements (67.2\%) (95\% CI 64.1-70.2). The chi-squared test showed a statistical significant difference between groups A and B ( $p=0.0321)$, and both performed significantly better than group $\mathrm{C}\left(p<1.046 \times 10^{-10}\right)$.

The individual relative TTR values are illustrated in Figure 4.

Mean INR is close to the target in all three groups but with a difference in the variation. Kruskal-Wallis rank sum test shows that there is no difference in the three groups mean values ( $p=0.09476)$, but that there is a difference in the SDs $(p=0.009794)$. (Before

\begin{tabular}{|c|c|c|c|c|c|c|c|c|c|}
\hline GROUP & $\begin{array}{c}\text { NO. OF } \\
\text { PATIENTS }\end{array}$ & MONTHS & $\begin{array}{l}\text { AVERAGE } \\
\text { MONTHS } \\
\text { PER } \\
\text { PATIENT }\end{array}$ & $\begin{array}{l}\text { DAYS IN TR } \\
(\%)(95 \% \\
\text { CONFIDENCE } \\
\text { INTERVAL) }\end{array}$ & $P$-VALUE & $P$-VALUE & $\begin{array}{l}\text { NO. OF INR } \\
\text { MEASUREMENTS } \\
\text { IN TR }(\%)(95 \% \\
\text { CONFIDENCE } \\
\text { INTERVAL) }\end{array}$ & $P$-VALUE & $P$-VALUE \\
\hline A & 46 & 507.2 & 11.03 & $\begin{array}{r}12,288(79.7) \\
(79.0-80.3)\end{array}$ & $\begin{array}{c}<2.2 \times 10^{-16} \\
(\text { A vs. C) }\end{array}$ & $\begin{array}{c}0.2516 \\
\text { (A vs. B) }\end{array}$ & $\begin{array}{r}1,635(78.3) \\
(76.5-80.1)\end{array}$ & $\begin{array}{l}1.046 \times 10^{-10} \\
\text { (A vs. C) }\end{array}$ & $\begin{array}{r}0.0321 \\
\text { (A vs. B) }\end{array}$ \\
\hline B & 37 & 406.0 & 10.97 & $\begin{array}{c}9,904(80.2) \\
(79.4-80.9)\end{array}$ & $\begin{array}{l}<2.2 \times 10^{-16} \\
(\text { B vs. C) }\end{array}$ & - & $\begin{array}{r}2,407(80.8) \\
(79.3-82.1)\end{array}$ & $\begin{array}{c}<2.2 \times 10^{-16} \\
\quad(B \text { vs. C) }\end{array}$ & - \\
\hline C & 40 & 461.0 & 11.52 & $\begin{array}{r}10,195(72.7) \\
(71.9-73.4)\end{array}$ & - & - & $\begin{array}{r}616(67.2) \\
(64.1-70.2)\end{array}$ & - & - \\
\hline
\end{tabular}

$p$-values are found with chi-squared test.

$T R$, therapeutic range. 


\section{CHRISTENSEN ET AL.}

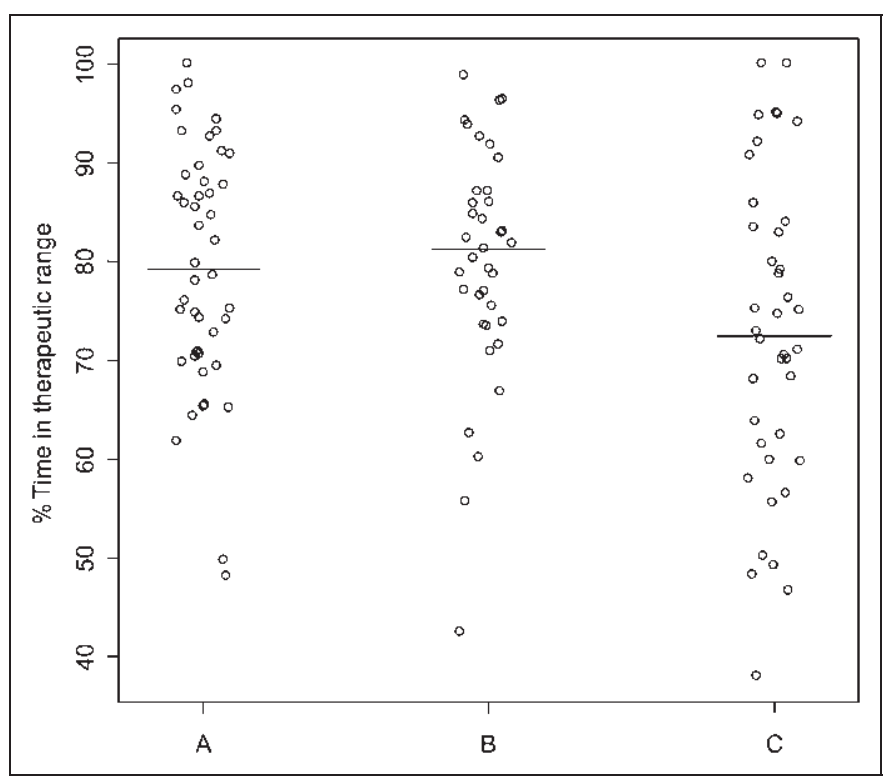

Fig. 4. Percent time in therapeutic range in groups A, B, and C. The horizontal line identifies median time in therapeutic range with each approach.

looking at the variance of the INR measurements one patient with extreme INR values was removed from group B.) Comparing SDs for the individual groups shows that the SD for group $\mathrm{C}$ differs from both groups A and B $(p<0.04516)$ (Table 4).

\section{ADVERSE EFFECTS}

No patients died during the trial. One patient was admitted to hospital during the trial. The reason for hospitalization was an INR over 9. The next day the patient's INR measured 5.1. No other adverse effects were reported.

\section{ANCILLARY ANALYSES}

The chi-squared test was used to test whether the proportion of number of INR measurements in and outside TR are equal in the groups for a similar period before the trial and in the trial. Group C was the only one that had the same proportions of INR measurement
Table 5. Chi-Squared Test on International Normalized

Ratio Measurements In and Outside Therapeutic Range,

for the Three Groups Before Trial and in the Trial

INR MEASUREMENTS

IN AND OUTSIDE TR (\%)

\begin{tabular}{l|c|c|c}
\multirow{2}{*}{ GROUP } & BEFORE TRIAL & IN TRIAL & \multirow{2}{*}{ P-VALUE } \\
\hline A & $323 / 133(70.8 / 29.2)$ & $1,635 / 452(78.3 / 21.7)$ & 0.0005576 \\
\hline B & $295 / 158(65.1 / 34.8)$ & $2,407 / 572(80.8 / 19.2)$ & $3.035 \times 10^{-14}$ \\
\hline C & $307 / 127(70.7 / 29.3)$ & $616 / 300(67.2 / 32.8)$ & 0.198 \\
\hline
\end{tabular}

in and outside TR as would be expected as that group continued in conventional treatment (Table 5). (Chi-squared test for TTR showed no equal proportions.)

\section{DOSING}

Comparison of mean doses for the individual patient before and in the trial is performed with the Wilcoxon rank sum test. The $p$-values are shown in Table 6. None of the groups showed a statistically significant change in doses from before the trial, nor did the SD of the individual patient dose show any significant change.

\section{Discussion}

This study is the second largest RCT study in observed patient years yet to evaluate the quality of oral anticoagulation using patient self-testing and Internet patient-to-doctor communication via direct patient access to the electronic record system. Further, one weekly measurement was compared to twice a week.

In total, 123 patients completed the trial spanning 114 patients years. These numbers narrow the confidence limits to a minimum and reduce $\mathrm{p}$-values. Using an electronic system for conventional hospital-based measurement and dosing, the TTR was $72.7 \%$ over an average of 1 year with 95\% CI of 71.9\%-73.9\%. Using once-aweek home measurement, the TTR was 79.7\%, 95\% CI 79.0\%-80.3\%, $p$-value for statistically significant difference based on actual number of days being $<2.2 \times 10^{-16}$.

Table 4. Overall Mean International Normalized Ratio and Mean Standard Deviation for the Three Groups in Trial
for Patients with Therapeutic Range $\mathbf{2 . 0 - 3 . 0}$
\begin{tabular}{|l|c|c|c|c|c|}
\multicolumn{1}{|c|}{ GROUP } & NO. OF PATIENTS & $\begin{array}{c}\text { MEAN (INR), } \\
\boldsymbol{P}=\mathbf{0 . 0 9 4 7 6}\end{array}$ & $\begin{array}{c}\text { MEAN (SD), } \\
\boldsymbol{P}=\mathbf{0 . 0 0 9 7 9}\end{array}$ & $\boldsymbol{P}$-VALUE (SD) & $\boldsymbol{P}$-VALUE (SD) \\
\hline A (TI 2.0-3.0) & 39 & 2.506 & 0.4421 & 0.04516 (A vs. C) & 0.1744 (A vs. B) \\
\hline B (TI 2.0-3.0) & 31 & 2.491 & 0.4169 & 0.003865 (B vs. C) & - \\
\hline C (TI 2.0-3.0) & 36 & 2.442 & 0.5453 & - & - \\
\hline
\end{tabular}

Comparing mean INR and SD with Kruskal-Wallis test and individual SDs between groups with Wilcoxon rank sum test.

$\mathrm{TI}$, therapeutic interval. 


\begin{tabular}{|c|c|c|c|c|c|c|}
\hline \multirow[b]{2}{*}{ GROUP } & \multicolumn{2}{|c|}{ MEAN WEEKLY DOSE MG/WEEK (RANGE) } & \multirow[b]{2}{*}{$P$-VALUE } & \multicolumn{2}{|c|}{ MEAN SD OF WEEKLY DOSE MG/WEEK } & \multirow[b]{2}{*}{$P$-VALUE } \\
\hline & BEFORE TRIAL & IN TRIAL & & BEFORE TRIAL & IN TRIAL & \\
\hline A & 39.1 (5.5-144.2) & $38.9(5.8-131.1)$ & 0.8813 & 2.15 & 1.95 & 0.8660 \\
\hline B & $35.6(10.8-60.2)$ & $36.8(16.8-66.6)$ & 0.1815 & 2.29 & 1.79 & 0.3992 \\
\hline c & $37.4(5.7-88.4)$ & $38.3(6.1-90.1)$ & 0.06728 & 1.68 & 1.93 & 0.5112 \\
\hline
\end{tabular}

Thus, the main conclusion of this study is that the TTR increased from 73\% to 80\%, a percentage difference 7\% (95\% CI 6.0\%-7.9\%).

No advantage was found measuring INR twice a week, the difference to once a week being nonsignificant $p=0.2516$. Twice a week being considerable more expensive, the advantage is too inferior to be applied in daily practice.

The stability of INR values over a year was better for self-testing, the SD of the single patient in the once a week group being 0.44 INR against the conventional control group 0.55 INR ( $p<0.045)$.

In the secondary outcome parameters, the number of INR measurements below 1.5 or above 5.0 showed no significant difference between groups A and B ( $p=0.92)$, and both were significant better than group $\mathrm{C}\left(p<2.0 \times 10^{-6}\right)$.

No patients died during the trial. Only one patient was admitted to hospital during the trial. The reason for hospitalization was an INR over 9, without bleeding. We believe that this remarkable finding is caused by the patients who chose to participate are younger and more engaged, knowledgeable, computer literate, and, in general, in better health.

The TTR of $80 \%$ is, to our knowledge, the highest published value in RCT until now. A recent article had a TTR with conventional versus PST of 59\% and 74\%, but with wide confidence intervals caused by a relatively low number of 66 observation years for 132 patients, and with measurement every 4.6 days. ${ }^{7}$ The Dabigatran study ${ }^{8}$ had only $60 \%$ in TTR, using conventional management.

The absolute value of TTR is important as it is a marker for the risk of bleeding and thrombosis. A 10\% difference in TTR thus corresponds to an increased risk of 1.29 for mortality, 1.10 for stroke, and 1.12 for other thrombolic events. ${ }^{9}$

We observed the same mean INR in the three groups, meaning that there was no tendency for the doctors to be more cautious in the control group.

Comparing outcome parameters in the single patient in the period 1 year before trial and during trial, the above observations from the RCT were reaffirmed, as the groups with once and twice weekly measurements improved (Table 5), whereas the control group showed no improvement. This demonstrated the absence of a Hawthorne or placebo effect. This was true even though the frequency of testing increased from every 21.3 days to every 15.3 days in the conventional control group. This can be explained by the doctors being more careful, repeating measurements more than usual.
A concern using point-of-care testing instruments is always that the measurements have a bias or an increased analytical imprecision. For the CoaguChek XS the analytical quality has been thoroughly documented, ${ }^{10-14}$ and our finding that patient SDs are smaller than during conventional treatment emphasizes this. Thus, the analytical imprecision is unimportant in relation to patient variation. ${ }^{15,16}$

A possible bias of the CoaguChek XS system was controlled by parallel measurements toward the Stago laboratory method and acceptable difference were seen (data not shown).

To monitor a possible drift in electronics during the trial period, the average dose of warfarin before and during the RCT was calculated. As Table 6 shows no increase or decrease in average weekly dose was seen for the single patient or the groups, demonstrating that the CoaguChek XS monitors were without clinical significant measurement bias.

The reduced SD for INR values during PST could be expected to reflect more frequent and finer adjustment of the INR dose. This is, however, not seen, as the SD of dose in $\mathrm{mg} /$ week did not change significantly though the PST; groups A and B showed lower values against group C's increased values. We do believe, however, that the more frequent testing enables smaller adjustments to keep INR in therapeutic range. A larger study is needed to confirm this.

When comparing patient self-management (PSM) (testing and self-dosing) against PST as in this article, it seems that quality of management is better with PST, 79.7\% of time in TR against $70.2 \%-$ 74\% for PSM. ${ }^{17-19}$

As PST is expensive in medical manpower as compared to PSM, we will now randomize our 180 patients currently in PST to continue in PST or self-dosing via the expert computer system, to see if quality can be maintained.

In conclusion, we believe that to have documented that managing patients anticoagulation by telemedicine and based on home measurement of INR is safe and possibly of a better quality as measured by TTR than patients' self-management. Patient preference and satisfaction using this telemedical solution will be reported in a separate article.

\section{Acknowledgments}

The authors would like to thank Biomedical Laboratory Scientist Hanne Leth Laursen for teaching patients to measure INR and to access the electronic patient journal and for registration of adverse 


\section{CHRISTENSEN ET AL.}

events. Our patients are thanked for their willingness to participate in the study. The study was financed by Lillebaelt Hospital.

\section{Disclosure Statement}

No competing financial interests exist.

\section{REFERENCES}

1. Wurster M, Doran T. Anticoagulation management: A new approach. Disease Manag 2006;9:201-209.

2. The Danish Society of Cardiology. Antitrombotisk behandling ved kardiovaskulære sygdomme "Trombokardiologi" DCS vejledning 2007. Nr. 2. Available at www.dskb.dk/media/documents/dcs.pdf (last accessed April 9, 2010).

3. Miyasaka Y, Barnes ME, Gersh BJ, Cha SS, Bailey KR, Abhayaratna WP, et al. Secular trends in incidence of atrial fibrillation in Olmsted County, Minnesota, 1980 to 2000, and implications on the projections for future prevalence. Circulation 2006;114:119-125.

4. Brandslund I. Development and implementation of an electronic decision support system for oral anticoagulation. Klinisk Biokemi i Norden. 2004;16: 12-15. Available at www.kkno.org/hefter2004/kkn2004-3.pdf (last accessed April 9, 2010).

5. Danish National IT and Telecom Agency. Available at http://en.itst.dk/ (last accessed April 9, 2010).

6. Rosendaal FR, Cannegieter SC, van der Meer FJM, Briët E. A method to determine the optimal intensity of oral anticoagulant therapy. Thromb Haemost 1993;69:236-239.

7. Ryan F, Byrne S, O'Shea S. Randomized controlled trial of supervised self-testing of warfarin therapy using an Internet-based expert system. J Thromb Haemost 2009;7:1284-1290.

8. Schulman S, Kearon C, Kakkar AK, Mismetti P, Schellong S, Eriksson H, et al. Dabigatran versus warfarin in the treatment of acute venous thromboembolism. N Engl J Med 2009;361:2342-2352.

9. Van Walraven C, Oake N, Wells PS, Forster AJ. Burden of potentially avoidable anticoagulant-associated hemorrhagic and thromboembolic events in the elderly. Chest 2007;131:1508-1515.

10. Ryan F, O'Shea $S$, Byrne $S$. The reliability of point-of-care prothrombin time testing. A comparison of CoaguChek $S$ and XS INR measurements with hospital laboratory monitoring. Int J Lab Hematol 2010;32:e26-e33.

11. Braun S, Watzke $H$, Hasenkam JM, Schwab M, Wolf T, Dovifat C, Völler H Performance evaluation of the new CoaguChek XS system compared with the established CoaguChek system by patients experienced in INR-self management. Thromb Haemost 2007;97:310-314.
12. Wieloch M, Hillarp A, Strandberg $K_{1}$ Nilsson C, Svensson PJ. Comparison and evaluation of a Point-of-care device (CoaguChek XS) to Owren-type prothrombin time assay for monitoring of oral anticoagulant therapy with warfarin. Thromb Res 2009;124:344-348.

13. Plesch W, Van den Besselaar AMHP. Validation of the international normalized ratio (INR) in a new point-of-care system designed for home monitoring of oral anticoagulation therapy. Int J Lab Hematol 2009;31:20-25.

14. Plesch W, Wolf T, Breienbeck N, Dikkeschei LD, Cervero A, Perez PL, Van den Besselaar AMHP. Results of the performance verification of the CoaguChek XS System. Thromb Res 2008;123:381-389.

15. Lassen JF, Brandslund I, Antonsen S. International normalized ratio for prothrombin times in patients taking oral anticoagulants: Critical difference and probability of significant change in consecutive measurements. Clin Chem 1995;41:444-447.

16. Lassen JF, Kjeldsen J, Antonsen S, Petersen PH, Brandslund I. Interpretation of serial measurements of international normalized ratio for prothrombin times in monitoring oral anticoagulant therapy. Clin Chem 1995;41: $1171-1176$

17. Hamad MAS, van Eeklen E, van Agt T, van Straten AHM. Self-management program improves anticoagulation control and quality of life: A prospective randomized study. Eur J Cardiothorac Surg 2009;35:265-269.

18. Jensen CF, Christensen TD, Maegaard M, Hasenkam JM. Quality of anticoagulant therapy in patients who perform self management: Warfarin versus phenoprocoumon. J Thromb Thrombolysis 2009;28:276-281.

19. Fitzmaurice DA, Murray ET, Allan TF, Hobbs FDR. A randomised controlled trial of patient self management of oral anticoagulation treatment compared with primary care management. J Clin Pathol 2002;55:845-849.

Address correspondence to: Ivan Brandslund, M.D., D.M.Sc. Department of Clinical Biochemistry Vejle Hospital Kabbeltoft 25 7100 Vejle Denmark

E-mail: ivan.brandslund@slb.regionsyddanmark.dk Received: July 30, 2010 Revised: September 21, 2010 Accepted: October 1, 2010 